\title{
Análise de clima organizacional e ações de endomarketing em uma empresa do campo: um estudo de caso na empresa GrandValle
}

\author{
Hesler Piedade Caffé Filho ${ }^{1}$; Ludimilla Macedo de Andrade ${ }^{2}$, Paula Nely Vasconcelos Theotonio ${ }^{3}$.
}

\begin{abstract}
Resumo: Este estudo tem como objetivo identificar as percepções dos colaboradores de campo em relação às ações de endomarketing realizadas pela fazenda GrandValle Agrícola, de Casa Nova (BA). A escolha da fazenda em questão se deu pela importância do negócio para a região e pela massiva contratação de trabalhadores rurais por ela e em todo o Vale do São Francisco. Para tanto, partimos de um pesquisa exploratória com estudo de caso de abordagem qualitativa. No intuito de avaliar o clima organizacional, foi aplicado um questionário estruturado, com amostra aleatória simples, a 20 trabalhadores do setor de manga e 46 colaboradores atuantes do segmento de uva. As dimensões contempladas foram: condições de trabalho, segurança, comunicação, liderança, relacionamento interpessoal, compensação e reconhecimento. Após identificar problemas como absenteísmo e falhas na comunicação entre trabalhadores e gestores, são sugeridas três ações que podem vir a sanar os problemas encontrados, bem como possíveis desdobramentos deste artigo científico.
\end{abstract}

Palavras-Chave: Endomarketing; Qualidade de Vida no Trabalho; Pesquisa de Clima Organizacional; Agronegócio.

\section{Organizational climate analysis and endomarketing actions: a case study in GrandValle Company}

\begin{abstract}
This study aims to identify the perceptions of the field collaborators in relation to the endomarketing actions carried out by the GrandValle Agrícola farm, in Casa Nova (BA). The choice of the farm in question was due to the importance of the business for the region and the massive hiring of rural workers for it and throughout the Valley of the São Francisco. To do so, we start with an exploratory research with case study of qualitative approach. In order to evaluate the organizational climate, a structured questionnaire was applied, with a simple random sample, to 20 workers from the mango sector and 46 employees from the grape segment. The dimensions contemplated were: working conditions, safety, communication, leadership, interpersonal relationship, compensation and recognition. After identifying problems such as absenteeism and failures in communication between workers and managers, three actions are suggested that may remedy the problems encountered, as well as possible unfolding of this scientific article.
\end{abstract}

Keywords: Endomarketing; Quality of life at work; Organizational weather research; Agribusiness.

\footnotetext{
${ }^{1}$ Administrador pela Estácio de Sá; MBA em Gestão Estratégica de Negócios pela Escola de Engenharia Eletromecânica da Bahia; Especialista em Marketing Institucional pela Faculdade São Francisco de Juazeiro (2009); Mestre em Gestão de Políticas Públicas da Universidade Federal do Recôncavo da Bahia. Administrador da Universidade Federal do Vale do São Francisco, Professor da Faculdade São Francisco de Juazeiro; Professor da Universidade Federal do Vale do São Francisco. Contato: hesler.caffe@ univasf.edu.br;

${ }^{2}$ Formada em Comunicação Social com ênfase em Relações Públicas e Marketing pela universidade Católica de Salvador; Discente do curso de Pós-graduação (Lato Sensu) em Gestão MBA de Gestão Empresarial e Marketing na Faculdade São Francisco de Juazeiro-Ba; Relações Públicas na Universidade Federal do Vale do São Francisco, lotada na Assessoria de Comunicação.
}

${ }^{3}$ Formada em Comunicação Social com ênfase em Jornalismo pela Universidade Estadual da Paraíba; Discente do curso de Pós-graduação (Lato Sensu) em Gestão MBA de Gestão Empresarial e Marketing na Faculdade São Francisco de Juazeiro-Ba. 


\section{Introdução}

As organizações modernas têm, cada vez mais, aumentado suas preocupações em ouvir seu colaboradores; fazer com que tenham parte na tomada de decisões e propor recompensas financeiras pelo bom desempenho. Estas, entre outras, são ações de endomarketing e que, comprovadamente, desenvolvem um nível de satisfação cada vez maior na organização resultando em aumento na produtividade e no comprometimento dessas pessoas dentro da empresa. Conforme esmiuçaremos mais à frente, o endomarketing é uma filosofia de gerenciamento, ou aglomerado de atividades, que considera os colaboradores como clientes internos e os seus contratos de trabalho como produtos internos, conforme indica PONCE

O senso comum entre os pesquisadores é que todos estes esforços para conquistar o colaborador aumentam, indiretamente, a competitividade da organização no mercado em que atua. E entre estes segmentos, o do agronegócio ${ }^{4}$ não fica de fora. Estudos indicam que a adoção de tecnologias, técnicas produtivas de uma gerência eficaz - com melhor aproveitamento e administração de recursos financeiros e humanos - são essenciais para potencializar resultados em organizações rurais (ZIBORDI, CARDOSO, ROCHA et al, 1997).

Preocupada em aprimorar o clima entre trabalhadores do campo, melhorar a produtividade, garantir sua competitividade no mercado e em atender às demandas por ações de relacionamento interno das certificadoras internacionais, a GrandValle Agrícola - empresa de produção e exportação de mangas e uvas situada em Casa Nova- BA, passou a investir em ações esporádicas de endomarketing.

De acordo com Guimarães (2004), estudiosos de clima organizacional consideram que as análises neste âmbito influenciam decisivamente no comportamento das pessoas nas empresas e instituições, contribuindo ou não para melhorias no ambiente corporativo. As progressões dizem respeito não apenas ao relacionamento interpessoal, como também à produtividade. A pesquisa tem sido o instrumento mais utilizado para avaliar o clima, principalmente através de questionários.

\footnotetext{
${ }^{4}$ Segundo Davis e Goldberg (1957), agronegócio é a "soma total das operações de produção e distribuição de suprimentos agrícolas, das operações de produção nas unidades agrícolas, do armazenamento, processamento e distribuição dos produtos agrícolas e itens produzidos a partir deles".
} 
Seguindo as recomendações acadêmicas e metodológicas mais adequadas, este estudo tem como objetivo identificar as percepções dos colaboradores de campo em relação às ações de endomarketing realizadas pela fazenda GrandValle Agrícola; e, ainda, avaliar as ações de endomarketing e gestão de pessoas já praticadas pela empresa. Após o diagnóstico ser levantado, serão sugeridas ações de endomarketing que possam vir a sanar os problemas encontrados.

Para este trabalho, utilizamos a metodologia da pesquisa exploratória. Para Gil (2008), este direcionamento metodológico tem como objetivo proporcionar maior familiaridade com o problema, com vistas a torná-lo mais explícito ou a construir hipóteses. Essas pesquisas podem ser classificadas como bibliográfica e estudo de caso (GIL, 2007), sendo este último tipo de pesquisa a nossa realidade neste trabalho.

A abordagem dos fatos apurados, por sua vez, será qualitativa; não se preocupando com representatividade numérica, mas, sim, com o aprofundamento da compreensão de um grupo. Para Minayo (2001), a pesquisa qualitativa atinge níveis mais profundos das relações, processos e fenômenos não redutíveis à operacionalização de variáveis.

Os dados desta pesquisa na GrandValle Industrial resultaram de aplicação de questionário estruturado, com amostra aleatória simples. Responderam às perguntas propostas 20 dos 45 funcionários do setor de colheita de manga e 46 de 100 colaboradores do setor de colheita de uva. Foram 29 questionamentos avaliando as percepções que os homens do campo têm dos seus ambientes de trabalho, fazendo uma análise quantitativa e qualitativa dos resultados.

As dimensões contempladas foram: condições de trabalho, segurança, comunicação, liderança, relacionamento interpessoal, compensação e reconhecimento. Estas dimensões foram escolhidas a partir de entrevistas com os proprietários da fazenda e com o diretor de gestão de pessoas, bem como de percepções das pesquisadoras em visitas anteriores à propriedade.

Devido às características do grupo analisado (nível de escolaridade reduzido e, inclusive, casos de analfabetismo funcional), este estudo optou por realizar entrevistas individuais ou em grupos pequenos, e pelo preenchimento de um formulário. Desta forma foi possível não só registrar as respostas, como verbalizar melhor cada item aos entrevistados. Além disso, os entrevistados foram incentivados a relatar os motivos pelos quais concordaram ou discordaram de suas afirmativas. 
Nos tópicos a seguir, vamos explorar um pouco mais o que dizem os teóricos sobre Endomarketing, Qualidade de Vida no Trabalho e Clima Organizacional. O intuito é apresentar a GrandValle Agrícola e os resultados do questionário de maneira mais contextualizada.

\section{A GRANDVALLE AGRÍCOLA}

A GrandValle Agrícola foi fundada em 1988, ainda sob o nome de Fazenda Fortaleza, no distrito de Santana do Sobrado, dentro do município de Casa Nova/BA. Desde então, apostou na produção de mangas e uvas de mesa, destinadas à comercialização no mercado brasileiro e no exterior. Seu fundador é Gilberto Secchi, natural de Joaçaba (SC), atual diretor-presidente da empresa.

De acordo com o site da empresa, a missão da GrandValle Agrícola é "desenvolver produtos naturais de qualidade através de práticas modernas e sustentáveis; em consonância com a ética e a transparência no relacionamento com os colaboradores, fornecedores, clientes e comunidade". Sua visão é "ser referência na produção sustentável de produtos naturais aliada à qualidade, diversidade e inovação". E seu valores são "qualidade, tradição, integridade, transparência, respeito, valorização dos colaboradores e sustentabilidade ambiental" (GRANDVALLE, 2017).

Atualmente, a fazenda possui 200 hectares produtivos de manga, nas variedades Tommy, Palmer, Keitt e Kent e 42 hectares de uva de mesa tipo Crisp, Sweet Globe, Sweet Jubilee, Red Globe e Vitória. Em uma área separada, há 8 hectares de uvas Isabel Precoce e Violeta, voltadas para a fabricação de suco de uva na GrandValle Industrial - empresa aberta em novembro de 2013, quando a fazenda já se encontrava consolidada no mercado de exportação e buscava alternativas para diversificar o agronegócio.

Para garantir competitividade no mercado, a fazenda aposta em certificações. São elas: Tesco NURTURE, HACCP e GlobalGAP, que requerem aperfeiçoamento constante em sustentabilidade, inocuidade do produto, segurança alimentar, proteção ambiental, bem-estar animal, saúde, segurança e responsabilidade social. A GlobalGAP, inclusive, acabou de certificar a GrandValle como de acordo com a norma GRASP (Avaliação de Risco em Práticas Sociais), que avalia a situação social dos trabalhadores em fazendas. 
Para garantir essa certificação, a fazenda deve garantir aos funcionários do campo: representatividade, procedimentos para lidar com reclamações, direitos humanos, acesso às regulamentações trabalhistas, contratos de acordo com as leis nacionais trabalhistas, salários justos e regulares, zero trabalho infantil, alfabetização para crianças que vivem na fazenda, horas reguladas de trabalho, auto-organização e negociações coletivas, além de ausência de discriminação.

Como complemento à caixa de sugestões e reclamações na recepção (implantada há alguns anos e 100\% respondida); em 2016, a GrandValle promoveu palestras de profissionais de saúde dentro das campanhas de Outubro Rosa e Novembro Azul. Estas iniciativas, no entanto, não foram baseadas em análises prévias do clima organizacional - apresentando pouco ou nenhum resultadoestratégico para a empresa.

Uma das questões que a empresa deseja combater, conforme relatou aos pesquisadores deste estudo, é o absenteísmo - ou ausência sistemática - no campo. Quick e Lapertosa (1982) acreditam que a situação é um fenômeno "multifatorial", podendo acontecer de maneira voluntária (por motivos particulares, como adoecimento por patologia ou acidente de trabalho); por questões legais (serviço militar, gestação, casamento ou morte) ou compulsoriamente (com suspensões, prisões, bem como demais questões que impeçam o trabalhador de comparecer ao serviço).

\section{Endomarketing}

O nível de sucesso de uma organização no mercado em que atua depende também da qualidade do relacionamento que ela mantém com os seus colaboradores, impactando diretamente no seu posicionamento de mercado. Uma organização que fortalece o relacionamento com o seu público interno e trata o seu colaborador como primeiro cliente sabe que pouca ou nenhuma estratégia de comunicação externa obterá êxito se não vier precedida do comprometimento do público interno.

Para que isso ocorra, algumas organizações se valem do conceito de endomarketing que foi definido por Saul Bekin em seu livro "Fundamentos do Endomarketing" no início da década de 90. De acordo com Bekin, Endomarketing é um conjunto de ações de marketing institucional dirigida para o público interno (estagiários, colaboradores, vendedores, 
representantes, fornecedores, acionistas). Em grego "endo" significa posição ou ação no interior, sendo assim, o endomarketing seria um "movimento para dentro".

Segundo Bekin (2004), o endomarketing objetiva a realização de trocas, visando à construção de relacionamentos leais com o público interno da organização. O endomarketing busca contribuir com uma boa imagem da organização na percepção dos seus colaboradores, envolvendo-os para que as relações no âmbito organizacional fiquem fortalecidas.

O marketing interno é um elemento que atua fortalecendo as relações interpessoais e fazendo com que todos os colaboradores de uma organização compartilhem uma mesma visão de alcance dos objetivos.

Projetos e ações que uma empresa deve empreender para consolidar a base cultural do comprometimento dos seus funcionários com o desenvolvimento adequado das suas diversas tecnologias visando: - a prática dos valores estabelecidos como base da nova cultura; - a manutenção de um clima ideal de valorização e reconhecimento das pessoas; a obtenção de índices maiores de produtividade e qualidade com a consequente redução de custos; - o estabelecimento de canais adequados de comunicação interpessoal, que permitirão a eliminação de conflitos e insatisfações, que possam afetar o sistema organizacional; - a melhoria do relacionamento interpessoal; - o estabelecimento da administração participativa; - a implantação de ações gerenciais preventivas. (Cerqueira 1994, p. 51)

O endomarketing foca todos os seus esforços no cliente interno, tratando-o como primeiro cliente, visando sua motivação e satisfação. Um colaborador desmotivado apenas cumpre as suas atribuições diárias de maneira limitada e não produz satisfatoriamente. Quando ele compartilha os mesmos objetivos organizacionais com a sua empresa, passa a produzir resultados esperados e oferece uma melhora da qualidade de serviço entregue ao cliente externo. "O principal objetivo de Endomarketing é fazer com que todos os funcionários tenham uma visão compartilhada sobre o negócio da empresa, incluindo itens como gestão, metas, resultados, produtos, serviços e mercados nos quais atua", afirmou Brum (1998, p. 15.

Para Grönroos (2003) o endomarketing enxerga os funcionários como um primeiro mercado, eles são o mercado interno das empresas. Dificilmente o marketing planejado para o público externo será bem-sucedido se não vier acompanhado de planos e ações de marketing voltado para o público interno.

O que as empresas precisam entender é que se ações de marketing forem pensadas e dirigidas ao seu público interno, oferecendo a esse público benefícios que o motive a perceber 
a sua relevância para o alcance dos objetivos organizacionais, ela não terá meros colaboradores e sim aliados que vestem a sua camisa, refletindo esse entusiasmo para o seu público externo e consequentemente aumentando a vantagem competitiva da organização.

\section{Qualidade de Vida no Trabalho}

O equilíbrio entre o homem e o seu trabalho, em um ambiente saudável, no qual os colaboradores buscam realizar com primor as suas atividades pelo fato de se sentirem bem e produtivos é conceituado como Qualidade de Vida no Trabalho.

Conforme Limongi-França (2003), a Qualidade de Vida no Trabalho (QVT) é a percepção do conjunto de escolhas de bem-estar relativas a hábitos saudáveis pessoais, familiares e organizacionais em ambiente ético Schirrmeister e Limongi-França (2012) conceituam a qualidade de vida no trabalho como procedimentos em gestão de pessoas que visam produtividade saudável, motivação, desenvolvimento humano e bem-estar pessoal e organizacional. Existem quatro pilares básicos que são elementos-chave para essa construção que são a resolução de conflitos, a reestruturação da organização do trabalho, a inovação nos sistemas de recompensa (financeiras e não financeiras) e a melhoria no ambiente de trabalho, como clima, cultura, ambiente, ergonomia e assistência.

De acordo com Chiavenato (2006, p.367) a QVT "afeta atitudes pessoais e comportamentos importantes para a produtividade, como; motivação para o trabalho, adaptabilidade e flexibilidade a mudanças no ambiente de trabalho"

Essa demanda é tão antiga quanto as próprias relações de trabalho, porém, os estudos mais difundidos no Brasil começaram a surgir na década de 70, quando Walton (1973) publicou indicadores de QVT com 8 critérios básicos.

Alguns outros modelos como os de Hackman e Oldham (1975) são conhecidos e aplicados. Neste modelo eles desenvolveram o Job Diagnostic Survey (JDS) e foram analisadas as dimensões básicas da tarefa no qual é possível verificar que elas precedem a satisfação e performance do trabalhador. Um pouco após esse estudo, Westley (1979) focou na organização do trabalho e no seu modelo foram agrupados quatro aspectos que prejudicam a Qualidade de Vida no Trabalho, sendo eles:

- Políticos: sentimento de insegurança no emprego; 
- Econômicos: sentimento de injustiça no sistema de recompensas, iniquidade;

- Psicológicos: ausência de autorrealização, levando à alienação;

- Sociológicos: ausência de participação nas decisões, gerando anomia.

Em um cenário no qual as relações de trabalho estão sendo mais valorizadas, a satisfação do trabalhador e o seu bem-estar estão sendo levados em conta. Uma nova percepção sobre as condições de vida no trabalho desperta a atenção para a Qualidade de Vida no Trabalho.

\section{Clima Organizacional}

Ótimas ferramentas para avaliar se ações de endomarketing e qualidade de vida no trabalho estão sendo eficazes, as pesquisas de clima organizacional analisam as influências do ambiente de trabalho sobre o comportamento humano, sendo o reflexo do conjunto de percepções compartilhadas por trabalhadores e um forte elemento detector e regulador do comportamento dentro das organizações. Litwin e Stringer (1968) definem que o clima organizacional é formado por fatores do ambiente de trabalho que podem ser medidos e são capazes de interferir no comportamento e na motivação dos indivíduos, e que podem ser observados diretamente por estes.

Segundo Chiavenato (2003), clima organizacional envolve uma visão mais ampla e flexível da influência ambiental sobre a motivação. É a qualidade ou propriedade do ambiente organizacional que é percebida ou experimentada pelos membros da organização e influencia no seu comportamento. Refere-se ao ambiente interno existente entre as pessoas que convivem no meio organizacional e está relacionado com o grau de motivação de seus participantes. Conforme Koys e DeCotiis (1991), o clima é um "fenômeno perceptual duradouro, construído com base na experiência, multi-dimensional e compartilhado pelos membros de uma unidade da organização, cuja função principal é orientar e regular os comportamentos individuais de acordo com os padrões determinados por ela".

Determinar como colaboradores expostos a uma série de estímulos têm percepções parecidas e atribuem significados similares a aspectos do clima organizacional que compõem é um fator relevante para o estudo das percepções que os trabalhadores constroem acerca de diferentes aspectos do seu trabalho. A pesquisa de clima organizacional é uma ferramenta que 
possibilita mensurar o nível de relacionamento entre o público interno e a organização. A pesquisa de clima tem sido realizada principalmente através de questionários que são constituídos por fatores/dimensões ou componentes do clima a serem avaliados e que variam conforme o modelo utilizado.

Conforme Bispo (2006) a análise, o diagnóstico e as sugestões, proporcionados pela pesquisa, são valiosos instrumentos para o sucesso de programas voltados para melhoria da qualidade, aumento da produtividade e adoção de políticas internas.

De modelos mais amplos e genéricos de pesquisa de clima organizacional a modelos mais específicos, eles se apresentam em forma de aplicação de questionário ou perguntas abertas que posteriormente terão os seus dados processados, revelando assim percentuais de satisfação dos respondentes que influenciam diretamente no clima organizacional.

Alguns modelos de pesquisa de clima organizacional foram desenvolvidos para serem aplicados em empresas de forma genérica, é o caso dos modelos de Kolb (KOLB et al., 1986), Sbragia (1983) e também do modelo de Litwin e Stringer (1968) que utiliza um questionário baseado em nove fatores/indicadores quais sejam: estrutura, responsabilidade, desafio, recompensa, relacionamento, cooperação, conflito, identidade e padrões. Outros modelos de pesquisa de clima organizacional como os de Coda (1997), Kozlowski e Doherty (1989), Levering (1984 e 1997) e Rizzatti (1995) dão ênfase em alguma categoria de organização ou em algum assunto mais específico do próprio estudo de clima organizacional e constituem importantes estudos sobre clima organizacional.

Resende e Takeshima (2000) ressaltam, como fatores importantes em uma pesquisa de clima, as condições de trabalho, os relacionamentos, a comunicação, o treinamento, salários e benefícios, a liderança, a gestão, a organização, a imagem da empresa, a qualidade, a produtividade, segurança e meio ambiente, os princípios e valores da organização.

Tamayo (1999) considera que na literatura estrangeira existem modelos construídos especificamente para estudar determinados tipos de organizações, como escolas, hospitais, bancos, organizações de negócios e organizações em geral. O autor considera que, mesmo existindo um modelo, é necessário que ele seja adaptado à organização a ser pesquisada. No caso deste estudo sobre a GrandValle Agrícola, foi necessário levar em consideração o baixo nível de escolaridade e a pouca prática de leitura entre grande parte dos colaboradores. 


\section{Análise dos Resultados}

O questionário foi aplicado em campo, após o intervalo da manhã para lanche, nos refeitórios dos setores de manga e uva da GrandValle Agrícola. Em formulários impressos, estavam 29 questionamentos avaliando o conjunto das percepções e interpretações que os trabalhadores têm do ambiente de trabalho, fazendo uma análise quantitativa e qualitativa dos resultados. Foram avaliadas setes dimensões globais de clima organizacional que permitem a compreensão de aspectos mais aprofundados do ambiente de trabalho que geram satisfação ou não nos funcionários. As dimensões que serviram como aspectos mensuradores para analisar os pontos fortes e fracos da Fazenda GrandValle Agrícola foram: comprometimento; segurança; comunicação; liderança; relacionamento interpessoal; compensação e reconhecimento. As dimensões privilegiadas foram: condições de trabalho, segurança, comunicação, liderança, relacionamento interpessoal, compensação e reconhecimento. Estes temas foram escolhidos a partir de entrevistas com os proprietários da fazenda e com o diretor de gestão de pessoas, bem como de percepções das pesquisadoras em visitas anteriores à propriedade.

Como respostas, os trabalhadores poderiam responder entre as alternativas: "concordo totalmente", "concordo com a maior parte", "discordo com a maior parte" ou "discordo totalmente". Responderam às perguntas propostas 20 dos 45 funcionários do setor de colheita de manga e 46 de 100 colaboradores do setor de colheita de uva.

O questionário aplicado foi o mesmo para todos; porém, para a análise dos resultados os trabalhadores foram divididos entre os que atuam na colheita da uva e os que atuam na colheita da manga. A divisão se faz necessária tendo em vista a diferença de grau de dificuldade no trabalho entre os dois segmentos, enquanto a colheita da manga requer mais força física para suportar o peso do equipamento, a colheita da uva requer um trabalho mais minucioso e delicado. Levando em consideração esses requisitos, a colheita da manga ficou designada para os homens e a colheita da uva ficou designada para as mulheres.

É possível destacar da análise dos dados que os entrevistados que atuam na colheita da manga possuem um maior nível de instrução, 35\% desses funcionários possuem ensino fundamental e 65\%possuem ensino médio. Esses valores contrastam com os obtidos entre as mulheres respondentes ao questionário e que atuam na colheita da uva, no qual apenas $44,44 \%$ possuem ensino médio e $55,56 \%$ possuem o ensino fundamental. Esses números são 
importantes para ilustrar que quanto maior o nível de instrução, maior é o nível de exigência do trabalhador. Da análise de dados é possível inferir que os funcionários atuantes na colheita da manga se mostraram mais críticos e exigentes com o trabalho, e as funcionárias atuantes na colheita da uva indicaram um nível mais elevado de satisfação com o trabalho que exercem, tendo uma visão altamente positiva do trabalho em sua totalidade.

De modo geral, os dados revelaram que os pesquisados têm um bom índice de concordância com as afirmativas, revelando que a maioria dos funcionários está satisfeita com a empresa e que de uma maneira geral, o clima na fazenda é positivo. A seguir, analisaremos separadamente cada dimensão, para revelar quais pontos merecem ser mantidos e quais pontos precisam ser revistos e melhorados.

a) COMPROMETIMENTO: No quesito comprometimento com a empresa no qual exercem suas atividades, os trabalhadores indicaram um alto grau de concordância com a dimensão pesquisada. A maioria absoluta dos funcionários demonstrou comprometimento com a Fazenda GrandValle Agrícola, informando que não passa pela cabeça deles sair da empresa. Esse é um bom índice que reflete no baixo nível de rotatividade de funcionários, o que consequentemente onera menos custos com treinamento e períodos de adaptação. Tamanho comprometimento se dá pela fazenda estar localizada em uma área com poucas ofertas de trabalho. Sendo assim, a Fazenda GrandValle Agrícola é a maior referência do seu ramo na região e os trabalhadores a valorizam por veem nela uma chance ímpar de trabalho digno e sério. Fato este que não exclui a preocupação com os trabalhadores que demonstraram discordância com a afirmação de não haver pretensão de sair da fazenda.

A maioria dos trabalhadores sentem orgulho de fazer parte do quadro de funcionários da empresa. Em especial, as trabalhadoras responsáveis pela colheita de uva responderam em sua totalidade absoluta que a fazenda é um ótimo lugar para se trabalhar. Não é comum encontrar uma empresa no qual $100 \%$ dos funcionários estejam comprometidos e sintam orgulho de fazer parte do time de colaboradores, mas isso aconteceu com as coletoras de uva e 90\% dos coletores de manga também responderam muito positivamente a esta questão, dando margem à inferirmos que os colaboradores em geral estão satisfeitos com a empresa GrandValle Agrícola.

b) SEGURANÇA: No quesito segurança para exercer suas atividades, os trabalhadores no geral demonstraram satisfação com a disponibilidade de equipamentos que a fazenda oferece para que eles realizem um bom trabalho. Nesse aspecto, se destacou a grande 
concordância com a afirmação de que o trabalho não prejudica a vida pessoal dos trabalhadores, tanto de uva, quanto de manga.

Podemos inferir que o maior nível de concordância no questionário com as afirmações do quesito segurança foram com as trabalhadoras que atuam na colheita da uva, 95,56\% delas estão satisfeitas com as equipamentos disponibilizados para segurança e acreditam que esse material é adequado para a função que exercem e 88,88\% delas demonstram satisfação com o ambiente de trabalho oferecido. É possível que grande parte dessa satisfação se dê pelo fato de que a colheita da uva é feita embaixo da sombra dos parreirais e elas não precisem usar nenhum equipamento pesado para exercer as suas atividades.

Apesar de apresentarem um bom nível de satisfação, os trabalhadores que atuam na colheita da manga merecem uma atenção especial no fator segurança, $20 \%$ deles não demonstram satisfação com a qualidade do ambiente oferecido. Boa parte dessa insatisfação pode estar relacionada as altas temperaturas e o peso do equipamento que carregam para fazer a colheita das mangas. Mas levando em consideração as elevadas temperaturas da região e o clima seco, a concordância com as afirmações nesta dimensão ainda foi positiva.

c) COMUNICAÇÃO: A comunicação não é percebida da mesma forma entre os trabalhadores que atuam na colheita da manga e os que atuam na colheita da uva. É possível que isso tenha uma ligação direta com a chefia imediata sob o qual estão vinculados. Quase a totalidade das trabalhadoras que atuam na colheita da uva acreditam que a fazenda GrandValle Agrícola costuma manter seus funcionários bem informados em relação ao trabalho e que eles sabem claramente o que podem ou não fazer na fazenda, $100 \%$ dos trabalhadores da uva informaram que recebem todas as orientações necessárias para realizar o seu trabalho. Em alguns quesitos, esses valores são discrepantes com os informados pelos funcionários que atuam na colheita da manga, um exemplo disso é que $40 \%$ destes acreditam que não são bem informados em relação ao trabalho que exercem e grande parte não se sente à vontade para fazer sugestões, críticas ou sugerir melhorias. É importante ressaltar que a falta de reuniões contribui consideravelmente para que o índice de concordância caia nesta dimensão tendo em vista que grande parte dos trabalhadores dos dois segmentos acredita que não ocorrem reuniões suficientes para que eles possam trocar ideias ou dar sugestões.

d) LIDERANÇA: Na dimensão referente à liderança, mais uma vez os trabalhadores que exercem a colheita da uva demonstraram um maior índice de concordância com as afirmações. Os trabalhadores do segmento da uva se mostraram muito satisfeitos com o 
trabalho feito pelos encarregados sob o qual estão supervisionadas, acreditando que o chefe imediato sabe lidar com os colaboradores que reportam a ele, confiando na sua competência, acreditando que ele é uma pessoa capaz de solucionar conflitos e problemas de relacionamento que surgem no ambiente de trabalho, incentivando as pessoas que trabalham com ele e a colaboração entre o grupo e escutando os funcionários na resolução de problemas.

É importante ressaltar que essa satisfação não encontra os mesmos índices entre os trabalhadores que atuam na colheita da manga, 25\% deles não conta com os encarregados para escutar os seus problemas, acreditando que esses encarregados não incentivam a colaboração e não confiam na competência deles. Outro fator que podemos observar na figura 4 é que $30 \%$ dos funcionários que atuam na colheita da manga não vê o seu superior imediato como uma pessoa que saiba entusiasmar e incentivar as pessoas que trabalham com ele.

e) RELACIONAMENTO INTERPESSOAL: Esta dimensão de clima organizacional obteve o maior índice de concordância entre os funcionários. A totalidade dos trabalhadores revela que prevalece na fazenda um clima de cooperação e camaradagem. Afirmam gostar dos colegas e do clima e do ambiente de trabalho.

Sobretudo, o clima de coleguismo entre os colaboradores, o bom relacionamento do grupo, e o bom relacionamento com a chefia são um dos pontos positivos da Fazenda GrandValle Agrícola.

f) COMPENSAÇÃO: Esta foi a dimensão de clima que obteve o menor índice de concordância entre os trabalhadores rurais. Um número expressivo de colaboradores percebe que não é justamente remunerado e recebe um salário baixo e mais da metade dos funcionários dos dois segmentos da colheita acreditam que às vezes faz algo a mais e não é recompensado por isso, ganhando a mesma coisa.

Percebe-se a partir dos dados que apesar de boa parte dos entrevistados gostarem de trabalhar na Fazenda GrandValle Agrícola, existe uma insatisfação geral com alguns dos benefícios oferecidos ou que a fazenda deixa de oferecer, e essa insatisfação predomina entre os trabalhadores que atuam na colheita da manga.

g) RECONHECIMENTO: Neste segmento, quase a totalidade dos trabalhadores afirmou se sentir bem realizando as tarefas que lhes foram delegadas, isso é um bom sinal e que indica satisfação com as suas atividades laborais. Porém, alguns aspectos desta dimensão devem ser encarados com mais atenção como o reconhecimento e valorização do trabalho dos funcionários que atuam na colheita da manga. $45 \%$ deles não se sente reconhecido e 
valorizado pela Fazenda GrandValle Agrícola e 40\% não percebe preocupação da fazenda emproporcionar-lhes crescimento profissional. Esses são sinais de insatisfação que precisam ser trabalhados.

\section{Conclusão}

Após a análise das sete dimensões mensuradoras de clima organizacional, podemos confirmar que as necessidades e demandas são diferentes para os dois segmentos de trabalhadores rurais, apesar de se aproximarem em muitos aspectos. Com o objetivo de melhorar o clima organizacional da Fazenda GrandValle Agrícola e minimizar os impactos do problema de absenteísmo, será necessário trabalhar alguns aspectos como a melhoria da comunicação entre os gestores e demais colaboradores, encontrar formas de ressaltar aos funcionários o quanto a empresa reconhece o valor de cada um e melhorar a percepção que eles têm em relação à compensação financeira oferecida pela GrandValle. Com base no resultado da pesquisa de clima organizacional, buscando potencializar todos os aspectos positivos que foram identificados nela e solucionar os conflitos que foram observados, foram criadas três sugestões de ações.

A primeira ação proposta é um café da manhã com a presença do diretor-presidente, acompanhado de integrantes da diretoria administrativa, como $\mathrm{RH}$ e marketing. O objetivo, aqui, é estreitar o relacionamento entre os gestores e os trabalhadores rurais; oportunizar um momento em que os colaboradores possam ser ouvidos, dar sugestões e fazer críticas; reconhecer o valor dos trabalhadores rurais; integrar a equipe; oferecer um momento de descontração fora da rotina; oportunizar a absorção dos valores e a visão da empresa; bem como atualizar os empregados sobre as novidades da fazenda. A ação deve ser feita em duas sextas-feiras por mês, das $7 \mathrm{~h} 30$ às $8 \mathrm{~h} 30$, em temporadas de três meses, com intervalo de dois meses. Os encontros devem ser feitos como por cultura, dentro do packing-house da manga, área ampla e que já serve como receptivo turístico.

Uma segunda ação é a promoção de aulas de ginástica laboral e disponibilização de um serviço de fisioterapia e enfermagem. A meta é reduzir o absenteísmo entre trabalhadoras gestantes, prevenir doenças e lesões nos trabalhadores rurais, oferecer ainda mais qualidade de vida aos trabalhadores e atenuar possíveis dores e lesões decorrentes da repetição dos 
movimentos da atividade laboral. A proposta é que um fiscal de campo seja treinado por um fisioterapeuta (que pode ser cedido pelo município de Casa Nova) para realização diária das práticas de ginástica laboral nos refeitórios das áreas de campo da manga e da uva, em horário definido pela empresa. Este profissional, ao lado do(a) enfermeiro(a), deverá fazer um atendimento quinzenal, das $07 \mathrm{~h}$ às $11 \mathrm{~h}$, às quartas-feiras. Nesses dias, deverão reportar ao marketing e ao RH as queixas e ações desempenhadas. A ação deve ser contínua, podendo ser realizada em temporada de três meses, com intervalo de dois meses para repetição.

A terceira sugestão é a premiação para os profissionais da colheita de uva com maiores níveis de produtividade no mês, valorizando o desempenho no trabalho e proporcionando um momento de descontração fora da fazenda. Ao longo de 5 meses, no dia do pagamento, um colaborador será agraciado - com ajuda dos fiscais e gerente de campo - com um voucher para jantar na Churrascaria e Pizzaria Matheus, em Santana do Sobrado, Casa Nova. O trabalhador poderá levar sua família.

Com a aplicação dessas atividades, acredita-se que haverá melhorias a curto prazo nos índices de motivação geral do trabalhador rural da GrandValle Agrícola, sem que haja custos elevados para a Fazenda. Crê-se, ainda, que os resultados e apontamentos deste estudo de caso exploratório e qualitativo possam ser levados em consideração para elaboração de políticas de qualidade de vida do trabalhador não apenas do Vale do São Francisco, mas de todo o país. Enquanto sugestão de futuros estudos, propomos um estudo de caso sobre a utilização de aplicativos como Whatsapp para comunicação entre fiscais e trabalhadores de campo - prática observada na coleta dos dados de pesquisa - enquanto mural digital de avisos.

\section{Referências}

BEKIN, Saul F. Conversando Sobre Endomarketing. São Paulo: Makron Books, 1995;

BEKIN, Saul Faingaus. Endomarketing: como praticá-lo com sucesso. São Paulo, SP: Prentice Hall, 2004;

BRUM, Analisa de Medeiros. Endomarketing como estratégia de gestão: encante seu cliente interno. Porto Alegre: Editora L\&PM, 1998;

CERQUEIRA, Wilson. Endomarketing: educação e cultura para a qualidade. Rio de Janeiro, RJ: Qualitymark, 1994; 
CHIAVENATO, Idalberto. Recursos humanos: O capital humano das organizações. 8. ed., 3. reimpr.- São Paulo: Atlas, 2006;

CLIMA ORGANIZACIONAL NA EMPRESA RURAL - UM ESTUDO DE CASO (PDF
$\begin{aligned} & \text { Download } \\ & \text { Available). }\end{aligned}$ from: https://www.researchgate.net/publication/286456165_Clima_Organizacional_na_empresa_r ural_-_um_estudo_de_caso [accessed Oct 15 2017];

DAVIS, J. H.; GOLDBERG, R. A. A concept of agribusiness. Boston: Harvard University,1957;

GRANDVALLE. Disponível em <http://grandvalle.com/empresa>. Acesso em 17/10/2017;

GIL, Antônio Carlos. Como elaborar projetos de pesquisa. 5. ed. São Paulo: Atlas, 2008;

GRÖNROOS, Christian. Marketing: gerenciamento e serviços. 2. ed. Rio de Janeiro: Elsevier, 2003;

GUIMARÃES, M. C. Clima organizacional em empresa rural - um estudo de caso. Caderno de Pesquisas em Administração, São Paulo, v. 11, no 3, p.11-27. 2004;

Hackman, R. \& Oldham, G.R. (1975). Development of the Job Diagnostic Survey. Journal of Applied Psychology, 60(2),159-170;

KOYS, D.; DECOTIIS, T. Inductive measures of psychological climate. Human Relations, 44 (3), p. 265-285, 1991;

KOLB, D. A. et al. Psicologia Organizacional:Uma Abordagem Vivencial. São Paulo,Atlas, 1986;

LIMONGI-FRANÇA, A.C. (2003). Qualidade de Vida no trabalho - QVT: Conceitos e práticas nas empresas da sociedade pós-industrial. São Paulo: Atlas;

LITWIN, G. H.; STRINGER, R. A. Motivation and organizational climate. Cambridge: Harvard University Press, 1968;

MINAYO, M. C. S. (Org.). Pesquisa social: teoria, método e criatividade. Petrópolis: Vozes, 2001;

PONCE, F. A. U. Marketing interno: um estudo de caso no setor de franqueado do ramo de perfumaria e cosméticos nas cidades de São Paulo e Osasco. São Paulo. 1995. Tese Doutorado em Administração) - Departamento de Administração da Faculdade de Economia, Administração e Contabilidade, Universidade de São Paulo;

PUENTE-PALACIOS, Kátia; FREITAS, Isa Aparecida de. Clima organizacional: uma análise de sua definição e de seus componentes. Organ. Soc., Salvador, v. 13, n. 38, p. 45-57, Sept. 2006 - Available from <http://www.scielo.br/scielo.php?script=sci_arttext\&pid=S1984$92302006000300003 \& \operatorname{lng}=$ en\&nrm=iso $>$.

access on 17 Oct. 2017. http://dx.doi.org/10.1590/S1984-92302006000300003; 
QUICK, T. C.; LAPERTOSA, J. B. Análise do absentismo em usina siderúrgica. Revista Brasileira de Saúde Ocupacional, 1982;

RESENDE, E.; TAKESHIMA, M. L. RH em tempo real: conceitos e ferramentas modernas para gestão de recursos humanos. Rio de Janeiro: Qualitymark Ed., 2000;

SBRAGIA, R. Um estudo empírico sobre clima organizacional em instituições de pesquisa. Revista de Administração, v. 18, n. 2, p. 30-39, 1983;

SCHIRRMEISTER, Renata; LIMONGI-FRANÇA, Ana Cristina. A qualidade de vida no trabalho: relações com o comprometimento organizacional nas equipes multicontratuais. Rev. Psicol., Organ. Trab., Florianópolis , v. 12, n. 3, p. 283-298, dez. 2012. Disponível em $<$ http://pepsic.bvsalud.org/scielo.php?script=sci_arttext\&pid=S1984-

$66572012000300004 \& \operatorname{lng}=$ pt\&nrm=iso>. acessos em 14 out. 2017;

TAMAYO, A. Valores e clima organizacional. In: PAZ, M. G. T.; TAMAYO, A. (Orgs.). Escola, saúde e trabalho: estudos psicológicos. Brasília: UnB, 1999. p. 241-269;

WALTON, R.E. (1973). Quality of Working Life: What is it? Sloan Management Review, 15(1),11-21;

WEIRICH, Claci Fátima; MUNARI, Denize Bouttelet; BEZERRA, Ana Lúcia Queiroz. Endomarketing: ensaio sobre possibilidades de inovação na gestão em enfermagem. Rev. bras. enferm., Brasília , v. 57, n. 6, p. 754-757, dez. 2004 . Disponível em $<$ http://www.scielo.br/scielo.php?script=sci_arttext\&pid=S0034-

$71672004000600026 \& \operatorname{lng}=\mathrm{pt} \& \mathrm{nrm}=\mathrm{iso}>$. acessos em 01 nov. 2017. http://dx.doi.org/10.1590/S0034-71672004000600026;

WESTLEY, W.A. (1979). Problems and Solutions in the Quality of Working Life. Human Relations, 32(2), 113-123;

ZIBORDI, M. S.; CARDOSO, J.L; ROCHA, J.V. et al. Estrutura do capital e volume dos negócios em um grupo de pequenas empresas rurais. In: CONGRESSO BRASILEIRO DE ADMINISTRAÇÃO RURAL, 2, 1997. Uberaba. Anais... Uberaba: ABAR, 1997. p. 96-105.

\section{Como citar este artigo (Formato ABNT):}

CAFFÉ FILHO, Hesler P.; ANDRADE, Ludimilla M. de; THEOTONIO, Paula N. V. Análise de clima organizacional e ações de endomarketing em uma empresa do campo: um estudo de caso na empresa GrandValle. Id on Line Revista ultidisciplinar e de Psicologia, 2017, vol.12, n.39, p.355371. ISSN: 1981-1179.

Recebido: 05.12.2017

Aceito: 11.12.2017 